\title{
Redefining of "EPSG" and "PROJ" for current State Coordinate Reference System of the Republic of North Macedonia
}

\author{
Bashkim IDRIZI \\ a University of Prishtina "Hasan Prishtina”, and Geo-SEE Institute Skopje, bashkim.idrizi@yahoo.com, bashkim.idrizi@uni-pr.edu
}

\begin{abstract}
The state Coordinate Reference System (CRS) of the Republic of North Macedonia (RNM) has been established a century ago, by the Military Geographic Institute of the Yugoslavia Kingdom. It is in official usage entire period up to day. In international public EPSG registry of geodetic datums, spatial reference systems, Earth ellipsoids, coordinate transformations and related units of measurement, CRS for RNM is recognizable within 3 EPSG codes 6204, 6316 and 8679.
\end{abstract}

First code EPSG 6204 represents current state CRS for the entire country area, based on current law, however unfortunately this CRS is official by the law but it is not used for developing the official spatial data published in geoportals of Agency for Real Estate Cadastre (AREC) and NSDI geoportal of RNM. The second code EPSG 6316 is defined to be used for 6 countries of former Yugoslavia that covers area between $19.5^{\circ} \mathrm{E}$ up to $22.5^{\circ} \mathrm{E}$ longitude, which does not correspond with the practical and official usage of CRS for working with spatial data in RNM and CRS law definition in RNM. Third code EPSG 8679 has never been used in RNM, which covers eastern part of RNM and Serbia beginning from $22.5^{\circ} \mathrm{E}$.

Beside of problems with EPSG codes, default transformation parameters of EPSG 6316 have low accuracy and can not be used for data overlapping with open layers. Therefore, redefined new EPSG codes for state CRS of RNM are proposed in this paper.

Keywords: EPSG, CRS, North Macedonia, State Coordinate Reference System, PROJ

\section{Introduction}

Coordinate Reference Systems (CRS) represents the mathematical model for location defining of spatial entities within the particular referent frame, which contain geodetic datum, and may contain map projection as well additional parameters. In practice it is known as spatial reference system (SRS) also, which is synonym of CRS [9]. Geographic and projected coordinate systems are two types of CRS's that are used in practice and coded for standardized usage in GI software (Idrizi 2020). Each CRS is associated with a local or global datum and should support an operation that exposes the domain of validity of that system (Staudinger 1999). The State Plane Coordinate Refence System is one or a set of geographic zones or coordinate systems designed for specific regions within national area, associated with a geodetic datum.

Standardized usage of CRS in GIS software gives opportunity to reach uniform and easier usage of same CRS by all users, without need for deep knowledge on CRS parameters. CRS's are specified in ISO 19111:2019 "Geographic information - Referencing by coordinates" [1], defined by the OGC [2] simple feature access using well-known text representation of coordinate reference systems, and referred to using EPSG codes defined by the International Association of Oil and Gas Producers [3]. It is very important to know that ISO 19111 was not defined for geodetic experts, it was made for producers and users of GIS, therefore the structure shall be clear and easy, as well as correct on a common level of abstraction (Ihde et all 2000). The EPSG dataset conforms to ISO 19111:2019, that is distributed as EPSG registry, EPSG database and in a relation model as SQL scripts (IOGP 2019), as Spatial Reference System Identifiers (SRIDs) and data definition for identifying coordinate reference systems, projections, and performing transformations between them, used by most of geographic information systems and GIS libraries as tool for standardized developing and usage of spatial data by all users. In parallel, PROJ (former PROJ.4) as generic coordinate transformation software that includes map projections and geodetic transformations (PROJ 2021) released under the $\mathrm{X} / \mathrm{MIT}$ open source license [4], is CRS string with geodetic transformation parameters used by the PROJ.4 projection engine in many GIS software.

Defined CRS's in EPSG and PROJ represents the official CRS that are in use or have been used in countries or regions, as well CRS's that are defined for international use such as Universal Transverse Mercator (UTM) map projection. Within the list of state CRS's, EPSG codes are defined based on reporting from national mapping agencies, which reflects the CRS's which are or have been 
in official use in national level for developing the spatial data in different scales. In a case of reporting for other CRS's by third parties, individuals or organizations, concerning to CRS that should depend to any country, including in EPSG [5] is impossible without verification by the national mapping agency, which is formally very stable rule.

An example of refused request for including new CRS for the case of North Macedonia is change request 2019.041 [6], proved with the necessity for proposed CRS, even new proposed CRS would help geo community to avoid orthogonal removing data for $4000 \mathrm{~km}$ and $/$ or $7000 \mathrm{~km}$ (Idrizi 2019) in a case of utilization spatial data compiled by national mapping agency not in accordance with the state CRS parameters. Within the history of change requests in EPSG database, there is only one request no 2013.019 by the Agency for Real Estate Cadastre (AREC), reported by AREC officer Mrs. Elizabeta Dukadinovska on year 2013 for including CRS of Macedonia, however there is no later reporting by AREC for CRS's of North Macedonia, even three changes have been made in the meantime that reflects to CRS's that depends to North Macedonia.

By reviewing current CRS's in EPSG database that covers national area of the Republic of North Macedonia, none of them can be fully used, and are not appropriate for part of official spatial data (Idrizi 2019), which prove the need for necessity changes in EPSG coding of North Macedonian CRS's. Requesting feedback by the North Macedonian national mapping agency AREC before applying changes is of big importance and is very valuable step, however if the national responsible institution does not support or ignore necessary changes, IOGP should give opportunities for changes in cases when request comes from third parties (non-official institution) but proven with proof in practical and/or scientific level. Proposed CRS's for North Macedonia should be compiled correctly on a common level of abstraction with the clear structure for wide usage by geo community and other experts who use spatial data, without need for detailed knowledge for CRS, according to basic rule of ISO 19111:2019.

\section{Coordinate Reference Systems of the Republic of North Macedonia}

\subsection{Formal CRS of North Macedonia}

The sate Coordinate Reference System (CRS) of the Republic of North Macedonia has been defined about one century ago, by the Military Geographic Institute (MGI) in Belgrade (Idrizi et all 2003).

The Republic of North Macedonia is using still the same CRS defined by the Military Geographic Institute in Belgrade at the third decade of the last century, underlined in all laws and regulations for basic geodetic works and laws and regulations for cadastral/topographical surveying from year 1920 until 2013 also, such as Law for land cadaster (official gazette no.34, year 1972), regulation for basic geodetic works (official gazette no.85, year 2007) etc, except the value of false easting. The parameters of current state coordinate system are defined in the articles 41 and 42 of the Law for real estate cadaster (Official gazette no.55, year 2013), articles 6,7 and 8 of the Regulation for compilation of topographic maps, ortho photo maps/plans and cartographic products (Official gazette no.159, year 2013), as well in the articles 23, 24, and 26 of the regulation for basic geodetic works (Official gazette no.151, year 2013; Idrizi 2019). In table 1, are given parameters of the state CRS of the North Macedonia.

\begin{tabular}{|l|l|}
\hline Datum & Hermannskogel \\
\hline Ellipsoid & Bessel 1841 \\
\hline Map projection & Gauss-Kruger $\left(3^{\circ}\right.$ zones $)$ \\
\hline Central meridian & $21^{\circ} \mathrm{E}$ \\
\hline Prime meridian & Greenwich \\
\hline Origin of latitude & Equator \\
\hline Scale factor & 0.9999 \\
\hline False easting & $500000 \mathrm{~m}$ \\
\hline False northing & $0 \mathrm{~m}$ \\
\hline Units & $\mathrm{m}$ (meter) \\
\hline Projecting zone & $7^{\text {th }}$ zone \\
\hline
\end{tabular}

Table 1. Parameters of North Macedonian state coordinate system (Idrizi and Ribarovski 2010)

\subsection{Nonformal CRS's of North Macedonia}

In practice, beside formal CRS, two CRS's are being defined due to Cartesian coordinate values used for developing spatial data, with the difference on using or excluding first digits 7 for Easting and/or 4 for Northing coordinate.

\subsubsection{Inherited CRS from Yugoslavia}

All spatial data for the area of North Macedonia before its independence on year 1991, have been compiled based on $7^{\text {th }}$ projecting zone of the Former Yugoslavia with given parameters in the table 2 below. The difference between this nonformal inherited and upper formal CRS, is distance between false easting values.

Even this CRS is nonformal and doesn't correspond with the Law provisions, official services of spatial data in North Macedonia, such as cadastre geoportal, NSDI geoportal and other geoportals of central and local institutions, provides spatial data with CRS parameters of inherited CRS from Yugoslavia. At the bellow figures are given examples of two geoportals:

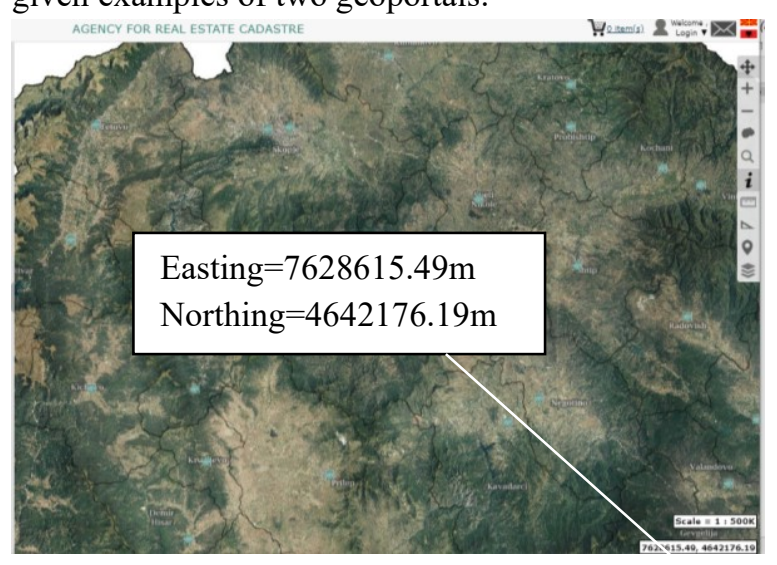

Figure 1. Distribution geoportal of AREC [7] 


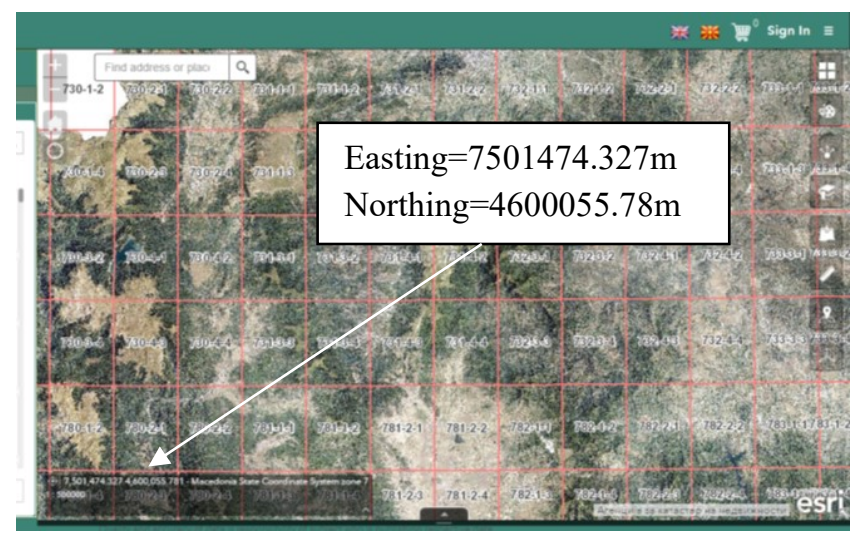

Figure 2. NSDI geoportal of North Macedonia [7]

\begin{tabular}{|l|l|}
\hline Datum & Hermannskogel \\
\hline Ellipsoid & Bessel 1841 \\
\hline Map projection & Gauss-Kruger $\left(3^{\circ}\right.$ zones $)$ \\
\hline Central meridian & $21^{\circ} \mathrm{E}$ \\
\hline Prime meridian & Greenwich \\
\hline Origin of latitude & Equator \\
\hline Scale factor & 0.9999 \\
\hline False easting & $7500000 \mathrm{~m}$ \\
\hline False northing & $0 \mathrm{~m}$ \\
\hline Units & $\mathrm{m}$ (meter $)$ \\
\hline Projecting zone & $7^{\text {th }}$ zone \\
\hline
\end{tabular}

Table 2. Parameters of inherited CRS from ex-Yugoslavia

In the example given in figure 2 from NSDI geoportal of North Macedonia, after the coordinate values, it is marked "Macedonia State Coordinate System zone 7", although easting coordinates are in contradiction with CRS parameters stated in article 42 of the Law for real estate cadaster published in Official gazette no.55 of year 2013, which means that position of spatial data in NSDI geoportal are not given in "Macedonia State Coordinate System".

\subsubsection{CRS without digits 7 for East and 4 for North coordinate values}

Beside both above mentioned formal CRS and nonformal inherited CRS, official spatial datasets defined in past period, especially in Microstation software in Agency for Real Estate Cadastre during the last decade of the last century and first decade of the current century, were digitized by excluding first digits of easting and northing coordinates. Practically this means not using digits 7 for representing of easting coordinates and 4 for representing of northing coordinates of spatial data (Idrizi 2019). This type of coordinate representing beside vector data, has been used for georeferencing raster data also, such as orthophoto maps, georeferenced cadastral maps etc. Such example of orthophoto maps for Bitola region is given in the figure 3 below.

Usage of such data in CAD software doesn't have any limitations, however the usage in GIS software is impossible without appropriate CRS parameters. This means that spontaneously third CRS for North Macedonian official spatial data has been established, with parameters identified by Idrizi in year 2019, that are given in table below.

\begin{tabular}{|l|l|}
\hline Datum & Hermannskogel \\
\hline Ellipsoid & Bessel 1841 \\
\hline Map projection & Gauss-Kruger $\left(3^{\circ}\right.$ zones $)$ \\
\hline Central meridian & $21^{\circ} \mathrm{E}$ \\
\hline Prime meridian & Greenwich \\
\hline Origin of latitude & Equator \\
\hline Scale factor & 0.9999 \\
\hline False easting & $500000 \mathrm{~m}$ \\
\hline False northing & $-4000000 \mathrm{~m}$ \\
\hline Units & $\mathrm{m}$ (meter $)$ \\
\hline Projecting zone & 7 th zone \\
\hline
\end{tabular}

Table 3. Parameters of coordinate reference system for North Macedonian spatial data defined with 6 digits in meter, by excluding digits 7 from easting and 4 from northing coordinate system (Idrizi 2019).

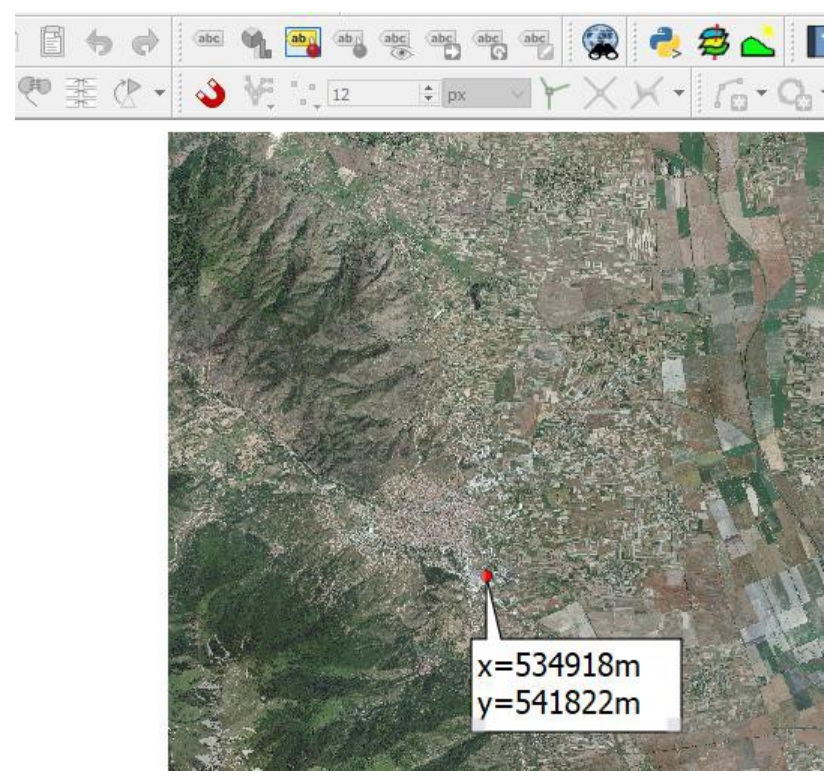

Figure 3. Example of spatial data in nonofficial CRS, by excluding digit 7 in easting and 4 in northing coordinates (Idrizi 2019)

\subsection{Differences between formal and nonformal CRS's of North Macedonia}

Three CRS's used in North Macedonia differs between them on false easting and false northing CRS values, which effects on $7000 \mathrm{~km}$ distance along easting and $4000 \mathrm{~km}$ distance along northing axis, between spatial data developed in three CRS's. In the next figure, distances between, and positions of three CRS's in plane coordinate system are shown. 


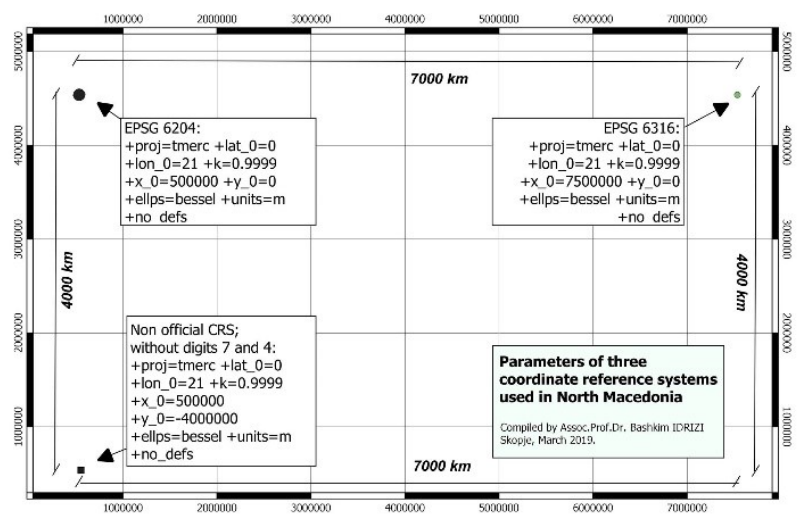

Figure 4. Positions and distances between spatial data in three CRS's used in North Macedonia (Idrizi 2019)

\section{EPSG codes for CRS of North Macedonia}

In international public EPSG registry of geodetic datums, spatial reference systems, Earth ellipsoids, coordinate transformations and related units of measurement, CRS for RNM is recognizable within 3 codes 6204, 6316 and 8679.

\subsection{EPSG 6204 - Macedonia State Coordinate System}

First code EPSG 6204 represents current state CRS for entire country area, based on current law with abovementioned CRS parameters in table 1, however unfortunately this CRS is official by the law but it is not used for developing the official spatial data published in geoportals of Agency for Real Estate Cadastre (AREC) and NSDI geoportal of RNM. Therefore, EPSG 6204 can not be used as CRS for working with official spatial data of RNM, although it is fully compatible with the law for real estate cadastre and entitled in EPSG registry as "EPSG 6204 Macedonia State Coordinate System" [10]. In next figure 5, structure of EPSG 6204 is given, while in figure 6 area covered is given.



Figure 5. Structure of EPSG 6204
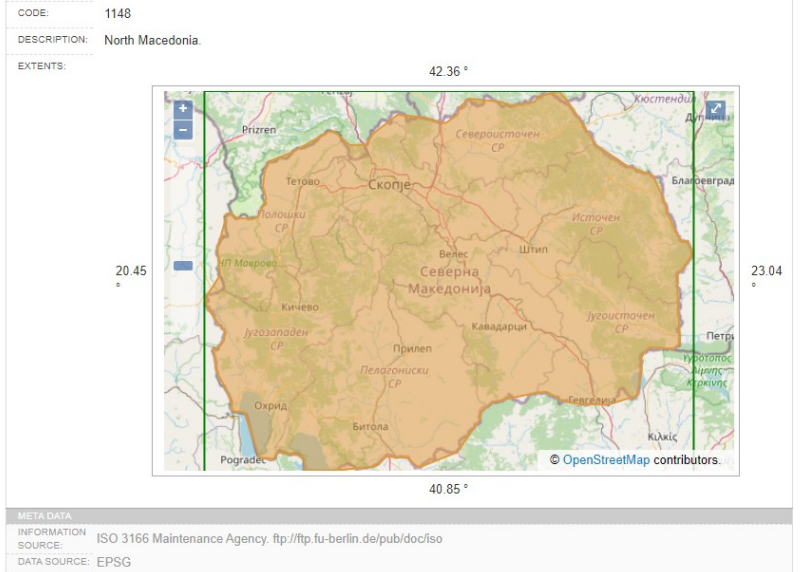

Figure 6. Area covered by EPSG 1148 in EPSG 6204 [10]

\subsection{EPSG 6316 - MGI 1901 / Balkans zone 7}

The second code EPSG 6316 entitled as "MGI 1901 / Balkans zone 7" [11], is defined to be used for 6 countries of former Yugoslavia which depends on the $7^{\text {th }}$ projecting zone of Gauss-Kruger projection, from $19.5^{\circ} \mathrm{E}$ up to $22.5^{\circ} \mathrm{E}$ meridian. About $13 \%$ of the eastern national area of RNM from meridian $22.5^{\circ} \mathrm{E}$ is not covered with EPSG 6316. State CRS of RNM does not use two projecting zones, even in former Yugoslavia $7^{\text {th }}$ projecting zone has not been limited for usage up to $22.5^{\circ} \mathrm{E}$ (Idrizi 2019). This means that EPSG 6316 area definition does not correspond with the practical and official usage of CRS for working with spatial data in RNM. In the geo practice in RNM, according to official spatial databases established by AREC as national mapping organization (NMO) of RNM, EPSG 6316 is in official usage, although false easting and area coverage of EPSG 6316 does not corresponds with the state CRS Law definition in the article 42 of the Law for real estate cadastre and the state border line / EPSG 1148. In next figure 7 the structure of EPSG 6316 is given, while in figure 8 area covered in EPSG 6316 is shown.

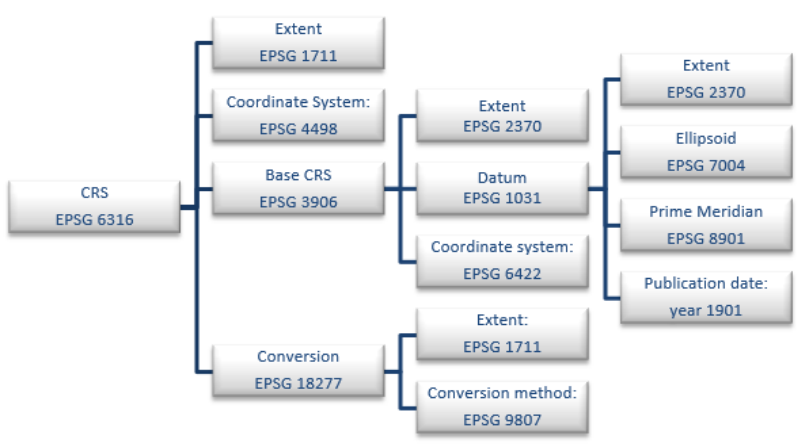

Figure 7. Structure of EPSG 6316 


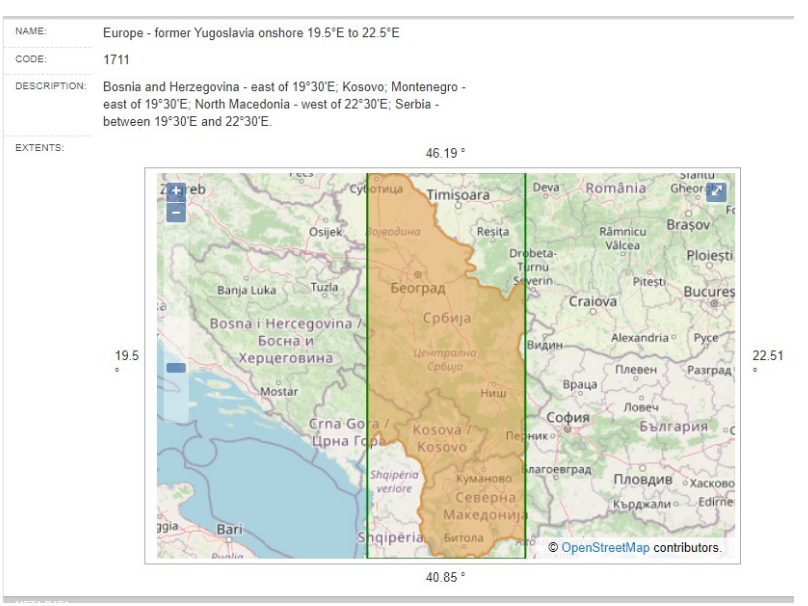

Figure 8. Area covered by EPSG 1711 in EPSG 6316 [11]

\subsection{EPSG 8679 - MGI 1901 / Balkans zone 8}

Third code "EPSG 8679 MGI 1901 / Balkans zone 8" [12] that covers eastern part of RNM and Serbia beginning from $22.5^{\circ} \mathrm{E}$, has never been used in RNM, even in former Yugoslavia. Although it covers about $13 \%$ of national area of RNM, it is unusable for national topographic, cartographic, cadastral and other purposes.

In next figure 9 the structure of EPSG 8679 is given, while in figure 10 area covered in EPSG 8679 is shown.

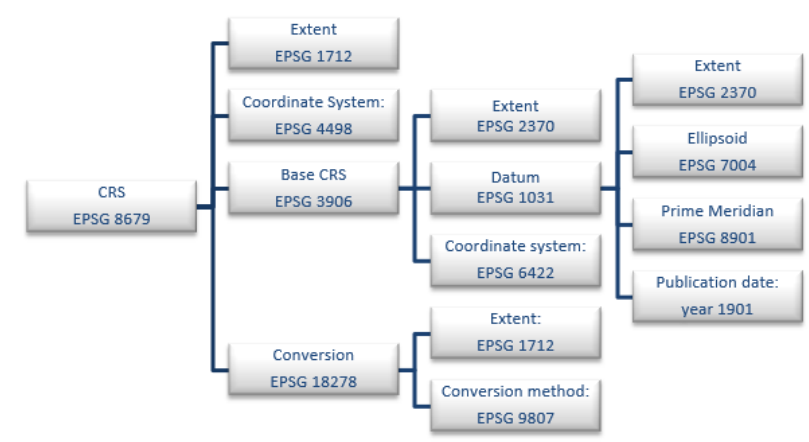

Figure 9. Structure of EPSG 8679

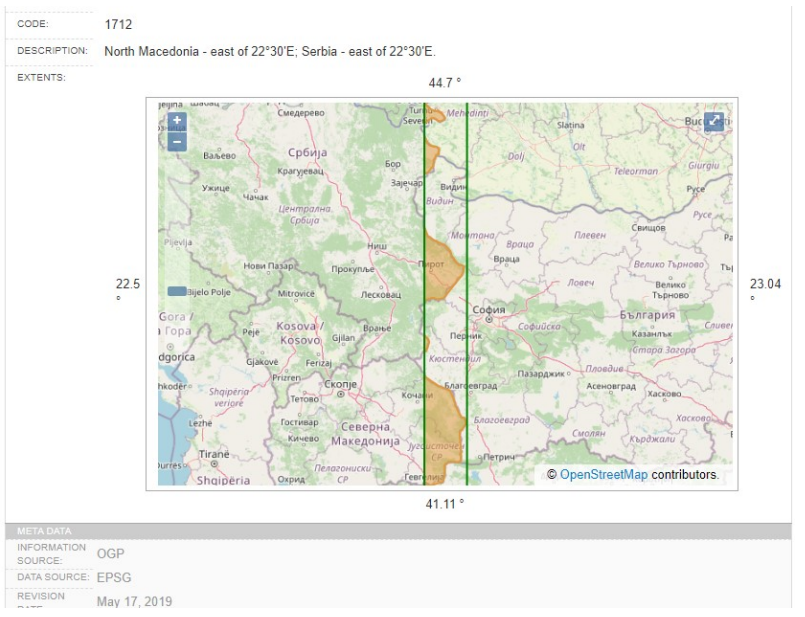

Figure 10. Area covered by EPSG 1712 in EPSG 8679 [12]

\subsection{Differences between EPSG 6204, 6316 and 8679}

Main difference between three CRS's are:

- codes for extent of CRS
- EPSG 1148 for EPSG 6204
○ $\quad$ EPSG 1711 for EPSG 6316
○ $\quad$ EPSG 1712 for EPSG 8679

- $\quad$ codes for conversion of CRS

$\begin{array}{cl}\circ & \text { EPSG } 6203 \text { for EPSG } 6204 \\ \circ & \text { EPSG } 18277 \text { for EPSG } 6316 \\ \circ & \text { EPSG } 18278 \text { for EPSG } 8679\end{array}$

- $\quad$ code for extend of conversion

$\begin{array}{cl}\circ & \text { EPSG } 1148 \text { for EPSG } 6203 \\ \circ & \text { EPSG } 1711 \text { for EPSG } 18277 \\ \circ & \text { EPSG } 1712 \text { for EPSG } 18278\end{array}$

Other parameters as Coordinate system (EPSG 4498), Base CRS (EPSG 3906 with all used codes (2370, 6422, 1031,7004, 8901, and 1901) for its defining), and conversion method (EPSG 9807) are same for three CRS's.

\section{Comparison between CRS of North Macedonia and EPSG codes for North Macedonia}

CRS's of North Macedonia shown in head 2 are not fully equal to CRS's defined in EPSG codes given in head 3 of this manuscript. In next table 4, the correlation between CRS's of NRM with CRS's with EPSG codes is given.

\begin{tabular}{|l|c|l|}
\hline CRS on RNM & & EPSG \\
\hline Formal CRS & $=$ & 6204 \\
\hline Non-formal CRS & $=$ & 6316 \\
\hline New identified CRS & $=$ & NO EPSG \\
\hline$N O C R S$ & $=$ & 8679 \\
\hline
\end{tabular}

Table 4. Correlation between CRS's of NRM with three CRS's of NRM in EPSG

\section{EPSG codes for transformation of North Macedonian spatial data from MGI 1901 to WGS84 and ETRS89}

In the EPSG registry, in total 43 transformations are available between geodetic datums that belongs to North Macedonian area as WGS 84, ITRF2005, ETRF2014, ETRF2000, ITRF2008, ETRS89, EVRF2019, MGI 1901 etc [www.epsg.org]. For practical purposes of geo community, transformations with EPSG codes 6205 and 6206 are defined by AREC and reported on year 2013 with change request no 2013.019 .

Transformation between MGI 1901 and WGS84 with seven parameters based on Bursa Wolf transformational model that guarantee $2 m$ accuracy, is defined as EPSG code 6206 [14], while the transformation between MGI 1901 and ETRS89 with seven parameters based on Bursa Wolf transformation and $1 \mathrm{~m}$ accuracy is defined as EPSG 6205 [13]. The transformation parameters of EPSG 6205 and 6206 are given in table 5 below: 


\begin{tabular}{|l|l|l|}
\hline & $\begin{array}{l}\text { EPSG 6205 } \\
\text { MGI 1901 to ETRS89 }\end{array}$ & $\begin{array}{l}\text { EPSG 6206 } \\
\text { MGI 1901 to WGS 84 }\end{array}$ \\
\hline X-axis translation & $517.4399 m$ & $521.748 m$ \\
\hline Y-axis translation & $228.7318 m$ & $229.489 m$ \\
\hline Z-axis translation & $579.7954 m$ & $590.921 m$ \\
\hline X-axis rotation & $-4.045^{\prime \prime}$ & $-4.029 "$ \\
\hline Y-axis rotation & $-4.304 "$ & $-4.488^{\prime \prime}$ \\
\hline Z-axis rotation & $15.612 "$ & $15.521 "$ \\
\hline Scale difference & $-8.312 \mathrm{ppm}$ & $-9.78 \mathrm{ppm}$ \\
\hline
\end{tabular}

Table 5. Transformation parameters between MGI 1901 to ETRS89 and WGS84 datums

\subsection{Datum transformations of EPSG 6204 and 6316 to CRS's with WGS84 datum}

CRS's in EPSG codding can use one ore more crossreferences to datum transformations, that allows single or multiply converting coordinates between two CRS's.

In a case of one datum transformation for one CRS, usage by GIS users is very easy without need for choosing most appropriate transformation, while in a case of more than one available option for datum transformation, users of GIS software should use the most appropriate conversion operation, depending on the area of use, origin of spatial data, as well as other constraints which may alter the fit for purpose for particular transformation operations. In second case, GIS users should have deep knowledge on geodetic datums, that is inconsistent with general rule of CRS's to be compiled correctly on a common level of abstraction with the clear structure for wide usage by geo community and other experts who use spatial data, without need for detailed knowledge for CRS, and not only by geodetic experts.

For transformation from EPSG 6204 to other CRS with datum WGS84, that means transformation between MGI 1901 to WGS84, only EPSG 6206 transformation is given as option, based on given parameters in table 5. This CRS with transformation parameters is shown in next table 6 in PROJ.4 format.

Transformation from EPSG 6316 to other CRS based on WGS84 datum has more transformation options as EPSG $3962,3964,7676,8823,8688,6206,3965,9143$ etc, since it is regional version that covers area more than one country. Utilization of "ask for datum transformation if several are available" tool in GIS software gives opportunities for selecting of most appropriate transformation, and it is very valuable tool for experts with good knowledge on CRS's and datum transformations, however it makes confusion to GIS users in general.

In a case of EPSG 6316 use without selecting appropriate datum transformation if several are available, default parameters shown in next table 6 for transformation to WGS 84 gives low accuracy of transformation. Unfortunately, most of EPSG 6316 users in North Macedonia use option with default transformation parameters given in table 5, in QGIS software, which make impossible overlapping of North Macedonian spatial data developed in EPSG 6316 with open layers based on WGS 84 datum within accuracy that is guarantee by AREC as provider of transformation parameters EPSG 6206.

\begin{tabular}{|c|c|}
\hline CRS & PROJ.4 \\
\hline $\begin{array}{l}\text { EPSG } \\
6204\end{array}$ & $\begin{array}{l}\text { +ellps }=\text { bessel } \\
\text { +towgs } 84=521.748,229.489,590.921,4.029,4.488 \\
-15.521,-9.78+\text { units }=m+\text { no_defs }\end{array}$ \\
\hline $\begin{array}{l}\text { EPSG } \\
6316\end{array}$ & $\begin{array}{l}+ \text { ellps }=\text { bessel }+ \text { towgs } 84=682,-203,480,0,0,0,0 \\
+ \text { units }=\text { m }+ \text { no_defs }\end{array}$ \\
\hline
\end{tabular}

Table 6. Default transformation parameters between MGI 1901 and WGS84 datums in EPSG 6204 and 6316.

\subsection{Problems of using datum transformations}

Beside above-mentioned problems with CRS definitions and practical usage by AREC and geo community in RNM given in head 3, datum transformation between MGI 1901 and WGS84/ETRS89 given in head 4 is one of the main limitations in everyday work with spatial data of RNM. Transformation parameters of EPSG 6204 based on PROJ.4 (+ellps=bessel +towgs $84=521.748,229.489,590.921,4.029,4.488$,$15.521,-9.78)$ are well defined, however this CRS cannot be used for processing of North Macedonian official spatial data due to problem with false easting value.

On the other side, default transformation parameters of EPSG 6316 based on PROJ.4 (+ellps=bessel +towgs $84=682,-203,480,0,0,0,0)$ have low accuracy and can not be used for data transformation aimed for overlapping with open layers by transformation of spatial data between North Macedonian and other CRS based on WGS84. Because of this limitations, existing EPSG coding of NRM state CRS's should be redefined and adopted to the current conditions with spatial data in RNM.

\section{Redefinition of EPSG and PROJ.4 codes for CRS's of North Macedonian spatial data based on state CRS parameters and official datum transformation parameters}

Above-mentioned problems with CRS definitions of North Macedonia in EPSG coding, datum transformations and current status of three type of official spatial data, itself states the need for defining new EPSG codes, in order to enable easy work with spatial data developed in different CRS's. This could be achieved with establishing two new CRS's and by keeping EPSG 6204 as it is established at this moment. By this system, EPSG 6316 which is currently in use in official geoportals of state and local self-government institutions will be used as regional CRS, instead current usage as national CRS for North Macedonia.

The EPSG 6316 should not be redefined, but it should remain as a regional CRS that covers areas of six countries from ex-Yugoslavia, with cross-referred available options for datum transformation.

In next table 7, which CRS's shown in Proj.4 format are given as CRS's that are necessary to be established, that will avoid current accuracy problems by geo community during using EPSG 6316 and overlapping with open layers. 


\begin{tabular}{|c|c|}
\hline CRS & PROJ STRING \\
\hline $\begin{array}{l}\text { EPSG } \\
6204\end{array}$ & 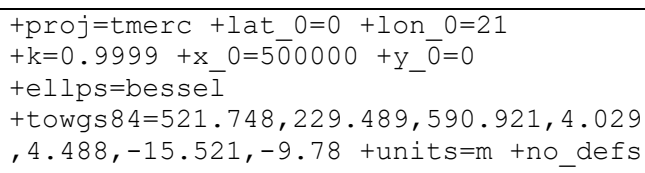 \\
\hline $\begin{array}{l}\text { New } \\
\text { EPSG } \\
1\end{array}$ & 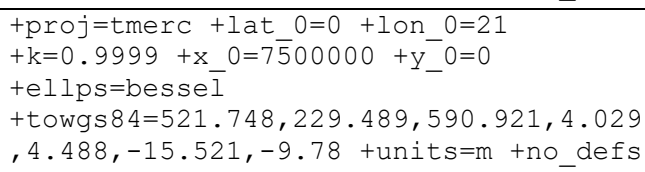 \\
\hline $\begin{array}{l}\text { New } \\
\text { EPSG } \\
2\end{array}$ & 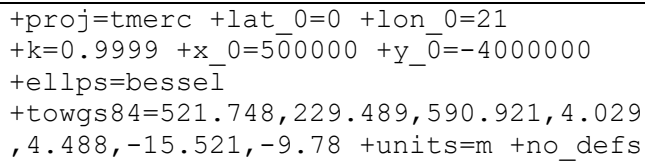 \\
\hline
\end{tabular}

Table 7. CRS's for North Macedonia with default transformation parameters (EPSG 6206) between MGI 1901 to WGS84 datum

In above table 7, due to correct definition of EPSG 6204 it should be kept as one of North Macedonian CRS's in EPSG registry, while two new CRS's as defined in table 7 should be defined additionally. "New EPSG 1" is defined to be compatible with inherited CRS from ex-Yugoslavia and default usage of datum transformation parameters "EPSG 6206" defined by AREC between MGI 1901 and WGS 84 mentioned in subheadings 2.2.1 and head 5, while "New EPSG 2" is defined to be compatible with "CRS without digits 7 for East and 4 for North coordinate values" (sub head 2.2.2. as well request change no 2019.041) and default values for datum transformation parameters "EPSG 6206" defined by AREC between MGI 1901 and WGS 84 mentioned in heading 5. For both new CRS's as extend area should be used EPSG 1148. For last new proposed EPSG 2, new EPSG code for conversion of CRS should be defined.

With three above CRS's with one datum transformation EPSG 6206, that belongs to three type of official spatial data in the North Macedonia, practical problems of GIS users will be fully eliminated.

By using opportunities for creating the custom CRS in GIS software, all of above-mentioned CRS's in table 7 are in use and are fully compatible between them and with open layers within the accuracy guarantee by the AREC transformation parameters. However, those should be officially recognized and coded with EPSG codes that belongs to national area of North Macedonia (EPSG 1148) with single datum transformation parameters (EPSG 6206), i.e. without multiply available options for datum transformation.

For the purposes of transformation between MGI 1901 and ETRS 89, which is also necessary for the practical purposes of GIS users, three new CRS's with new EPSG codes based on datum transformations parameters EPSG 6205 defined by AREC, should be also defined. In next table 8, additional three CRS's with only one datum transformation (EPSG 6205) available option are given.

\begin{tabular}{|c|c|}
\hline CRS & PROJ STRING \\
\hline $\begin{array}{l}\text { New } \\
\text { EPSG } \\
\mathbf{3}\end{array}$ & $\begin{array}{l}\text { +proj=tmerc +lat } 0=0+\text { lon } 0=21 \\
+\mathrm{k}=0.9999+\mathrm{x} 0=500000+\mathrm{y} \overline{0}=0 \\
+ \text { ellps=besse }+ \text { +togrs } 80=5 \overline{1} 7.4399, \\
228.7318,579.7954,-4.045-4.304, \\
15.612,-8.312 \text { tunits }=m+\text { no defs }\end{array}$ \\
\hline $\begin{array}{l}\text { New } \\
\text { EPSG } \\
\mathbf{4}\end{array}$ & 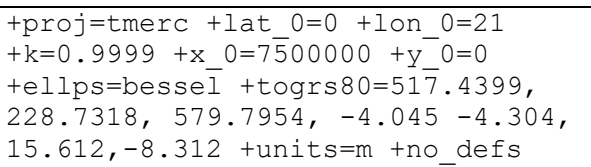 \\
\hline $\begin{array}{l}\text { New } \\
\text { EPSG } \\
\mathbf{5}\end{array}$ & $\begin{array}{l}+ \text { proj=tmerc +lat } 0=0 \text { +lon } 0=21 \\
+\mathrm{k}=0.9999+\mathrm{x} 0=500000+\mathrm{y} \overline{0}=-4000000 \\
+\mathrm{ellps}=\text { besse } \overline{1}+\text { togrs } 80=517.4399, \\
228.7318,579.7954,-4.045-4.304, \\
15.612,-8.312 \text { tunits }=m+\text { no defs }\end{array}$ \\
\hline
\end{tabular}

Table 8. CRS's for North Macedonia with default transformation parameters (EPSG 6205) between MGI 1901 to ETRS89 datum

\section{Conclusions}

New proposed CRS's for North Macedonian spatial data developed by AREC and other institutions in central and local level, is more than necessary for practical issues which will simplify usage of GIS tools for overlapping spatial data developed in different CRS's, even in WGS84 and ETRS 89 geodetic datums. Proposed options are in use provided by Geo-SEE Institute to its stakeholders as custom defined CRS's; however, those should be officialised by establishing new EPSG code structures for each purpose with single available geodetic datum transformation. With this kind of definition, GIS users will be able to use/overlap spatial data from different CRS's, even from different geodetic datums, without requirement for deep knowledge on CRS's and transformations between them.

Although North Macedonia in near future will change its datum to ETRS89, for the historical purposes and further usage of spatial data developed in past period, new EPSG codes are more than necessary to be established as soon as possible with above given parameters.

All proposed new EPSG codes are in line with ISO 1911, developed for producers and users of GIS, and not only for geodetic experts, with clear, easy and correct CRS structure on a common level of abstraction for usage by non-professional users.

\section{References}

Idrizi, B. (2020). International EPSG coding of the state coordinate reference system of the Republic of Kosova, Proceedings Vol.1 $8^{\text {th }}$ ICCandGIS, June, 2020, Nessebar, Bulgaria. https://iccgis2020.cartographygis.com/8ICCGISVol1/8ICCGIS_Proceedings_Vol1_(49).pdf

Staudinger, M. (1999). Spatial reference systems: the OGC's efforts and concepts of measurement-based GIS. Spatial reference systems for Europe proceedings, http://www.crs-geo.eu/pub03ProceedingsWS1999.pdf 
Idrizi, B. (2019). Harmonization of different type of coordinate systems used in North Macedonia. Proceedings of International Cartographic Association International Conference, July, 2019, Tokyo, Japan. https:/www.proc-int-cartogr-assoc.net/2/46/2019/icaproc-2-46-2019.pdf

Ihde J., Boucher C., Dunkley P., Farrell B., Gubler E., Lutherdt J., Torres J. (2000). European spatial reference systems - frames for geoinformation systems. http://www.crsgeo.eu/pub01EuropeanSpatialRefernceSystems.pdf

Idrizi, B.and Ribarovski, R. (2010). Historical overview, quality and current condition of the geodetic networks in Macedonia. FIG Working Week Proceedings, April 11-16, 2010, Sydney, Australia.

https://www.fig.net/resources/proceedings/fig_proceedi ngs/fig2010/papers/ts01h/ts01h_idrizi_ribarovski_4242. pdf

International Association of Oil and Gas Producers IOGP. (2019). Coordinate conversion and transformation including formulas. IOGP Publication 373-7-2 - Geomatics Guidance Note number 7, part 2. https://www.iogp.org/wp-content/uploads/2019/09/37307-02.pdf

Idrizi, B. Pashova, L. Kabashi, I. Mulic, M. Krdzalic, D. Tutic, D. Vucetic, N. Kevic, K. Nikolic, G. Djurovic, R. (2018). Study on length differences from topography to map projection within the state coordinate systems for some countries on the Balkan Peninsula. FIG working week 2018. Istanbul. Turkey.

https://fig.net/resources/proceedings/fig_proceedings/fig 2018/papers/ts08e/TS08E_idrizi_pashova_et_al_9602.p df

PROJ contributors (2021). PROJ coordinate transformation software library; Release 8.1.0. https://proj.org.

Idrizi, B. Imeri, R. Angelevski, D. Skenderi, F. and Hamiti, F. (2003). Analyzing of map projection of the Republic of Macedonia. Second International Conference of SHAIN. Tetova, Macedonia.

Idrizi, B. (2013). Length differences between topography surface and map projections: Case study Country area of Macedonia. 5th International conference on cartography and GIS; Riviera, Bulgaria. https://cartographygis.com/docsbca/5ICCandGIS_Proceedings.pdf

Official gazette no55. Year 2013. Law for real estate cadaster. Agency for real estate cadaster. Skopje. North Macedonia. https://www.katastar.gov.mk/wpcontent/uploads/Regulativa/zakoni/zakoni/Zakon\%20za $\% 20 \mathrm{KN} \% 202013$.pdf

Official gazette no151. Year 2013. Regulation for basic geodetic works. Agency for real estate cadaster. Skopje. North Macedonia. https://www.katastar.gov.mk/wpcontent/uploads/Regulativa/Pravilnici/osnovni\%20geod etski\%20raboti.pdf

Official gazette no.159. Year 2013. Regulation for compilation of topographic maps, ortho photo maps/plans and cartographic products. Skopje. North Macedonia. https://www.katastar.gov.mk/wpcontent/uploads/Regulativa/Pravilnici/topografski\%20k arti15913.pdf

Official gazette no34. Year 1972. Law for land cadaster. Agency for real estate cadaster. Skopje. North Macedonia. https://www.katastar.gov.mk/wpcontent/uploads/Regulativa/zakoni/zakoni\%20von\%20si la/za01_premer_zemjiste_.pdf

Official gazette no85. Year 2007. Regulation for basic geodetic works. Agency for real estate cadaster. Skopje. North Macedonia. https://www.katastar.gov.mk/wpcontent/uploads/Regulativa/Pravilnici/PRAVILNIK $\% 20$ ZA\%20OSNOVNI\%20GEODETSKI\%20RABOTI\%20 maj\%202007.pdf

[1] https://www.iso.org/standard/74039.html (Accessed on August 2021)

[2] https://www.ogc.org/standards/wkt-crs (Accessed on August 2021)

[3] https://epsg.org/search/by-name (Accessed on August 2021)

[4] https://en.wikipedia.org/wiki/MIT_License

(Accessed on August 2021)

[5] https://epsg.org/dataset-change-requests.html (Accessed on August 2021)

[6] https://epsg.org/closed-changerequest_2019.041/Add-North-MacedoniaCRS.html? sessionkey $=\mathrm{d} 2$ zyjwvvel (Accessed on August 2021)

[7] https://ossp.katastar.gov.mk/OSSP (Accessed on August 2021)

[8] https://nipp2.katastar.gov.mk:5001/nipp2/en (Accessed on August 2021)

[9] https://datacarpentry.org/organization-geospatial/03crs/ (Accessed on August 2021)

[10] https://epsg.org/crs_6204/Macedonia-StateCoordinate-System.html?sessionkey=zgyahvrr7m (Accessed on August 2021)

[11] https://epsg.org/crs_6316/MGI-1901-Balkans-zone7.html?sessionkey=zgyahvrr7m (Accessed on August 2021)

[12] https://epsg.org/crs_8679/MGI-1901-Balkans-zone8.html? sessionkey $=$ zgyahvrr7m (Accessed on August 2021)

[13] https://epsg.org/transformation_6205/MGI-1901-toETRS89-5.html?sessionkey=oqugm $792 \mathrm{i} 1$

[14] https://epsg.org/transformation_6206/MGI-1901-toWGS-84-10.html?sessionkey=oqugm $792 \mathrm{i} 1$

[15]

https://nipp2.katastar.gov.mk:5003/nipp3/registry/coord inatesystem/EPSG_6205/EPSG_6205.mk.html

[16]

https://nipp2.katastar.gov.mk:5003/nipp3/registry/coord inatesystem/EPSG_6206/EPSG_6206.mk.html 